\title{
Indonesian Genomic Landscape of Pathogenic Mutation of APC, KRAS, TP53, PIK3CA, and MLH1 in Colorectal Cancer
}

Vania Myralda Giamour Marbun ( $\sim$ vania.myralda@gmail.com )

Rumah Sakit Umum Pusat Nasional Dr. Cipto Mangunkusumo

Toar Jean Maurice Lalisang

Rumah Sakit Umum Pusat Nasional Dr. Cipto Mangunkusumo

Linda Erlina

Indonesian Medical Education and Research Institution (IMERI), Universitas Indonesia

\section{Research Article}

Keywords: colorectal cancer, genetic mutation, pathogenic mutation, next-generation sequencing, APC, TP53, PIK3CA, KRAS, MLH1

Posted Date: September 27th, 2021

DOl: https://doi.org/10.21203/rs.3.rs-900277/v1

License: (c) (i) This work is licensed under a Creative Commons Attribution 4.0 International License. Read Full License 


\section{Abstract}

Background : Knowing colorectal cancer's heterogeneity and dynamic features, recognizing its biological behaviour requires detailed identification of mutated genes involved. Colorectal cancer (CRC) requires several mutated genes to occur and those are dissimilar in each person hence essential to be discovered in specific population. Until recently, there is no known study describing genomic landscape of CRC in Indonesian population. This study aims to describe profile of pathogenic mutation of APC, TP53, PIK3CA, $K R A S$, and $M L H 1$ in CRC patients treated at 3 different hospitals in Jakarta.

Methods : This is a descriptive study conducted on CRC patients who underwent neoadjuvant, surgical, and adjuvant therapy at RSCM, RSKJ, and MRCCC in 2017-2018. DNA analysis was performed using next-generation sequencing and aligned against GRCh38. Pathogenic variant was identified using ACMG classification and FATHMM score. Data related to behaviour and survival were collected from medical records.

Results : There were total 22 subjects in which APC, TP53, and PIKCA were mutated. KRAS mutation occurred in $64 \%$, while MLH1 in $45 \%$. Five types of mutation were identified, including nonsense, missense, frameshift, splice-site, and silent mutation. There are 4 groups of co-occurring mutations, which are APC, TP53, PIK3CA (triple mutation/TM) alone; TM+KRAS; TM+MLH1; and TM+KRAS+MLH1, presenting different nature and survival.

Conclusion : Indonesia having various ethnicities with diverse diet and lifestyle has distinct profile of pathogenic mutation presenting mostly with locally-advanced stage with various outcome and survival rate.

\section{Introduction}

Colorectal cancer has been known as one of the most well-studied malignancy. Its dynamic and heterogeneity are characterized by many interconnecting molecular etiopathogenesis exhibiting different behavior inter and intratumor. ${ }^{1-5}$ Based on recent biomolecular study, genetic and epigenetic analysis can evaluate the nature of the tumor, hence able to predict heredity, progressivity, recurrency, response to therapy, and even survival rate. Those variables cannot be estimated by AJCC staging system alone. For this reason, precision medicine rooting to genomic profile of each individual, are starting to advance.

Colorectal malignancy, which involves at least three or four genetic mutation, are feasible for nextgeneration sequencing methods. ${ }^{2,6}$ Two of the three most common carcinogenic pathways are chromosomal and microsatellite instability. ${ }^{7-10}$ Five genes which frequently involved are APC, TP53, KRAS, PIK3CA, and MLH1. Different group of age, gender, and geographic location actually have different variations of mutation and genes involved so that study on specific population is important in advancing precision medicine. ${ }^{11}$ Until recently, there is no publication providing genomic landscape of colorectal 
cancer in Indonesian population. This study aims to analyze genomic profile of colorectal cancer in Indonesia.

\section{Methods}

This is a descriptive study in patients with colorectal malignancies who underwent surgery and/or chemoradiation and/or chemotherapy at RSCM, RSKJ, and MRCCC in 2017-2018 whose tumor tissue specimens were still properly stored in the form of formalin-fixed paraffin-embedded (FFPE). This study has been reported in line with STROCSS criteria. ${ }^{12}$

\section{Sample Preparation}

All sequencing preparation was performed by Department of Medical Chemistry, Faculty of Medicine, Universitas Indonesia at Bioinformatics Core Facility of Indonesia Medical Education and Research Institute (IMERI).

DNA extraction was performed using QIAamp DNA FFPE Tissue Kit. The quality of extracted DNA was evaluated using an absorbance ratio of $260 \mathrm{~nm}$ to $280 \mathrm{~nm}\left(\mathrm{~A}_{260} / \mathrm{A}_{280}\right)$ and $260 \mathrm{~nm}$ to $230 \mathrm{~nm}$ $\left(A_{260} / A_{230}\right)$. Purity criterion for samples with the $A_{260} / A_{280}$ ratio is within the range of $1.8-2.0$ and $A_{260} / A_{230}$ ratio is within the range of 2.0-2.2. After purity criterion fulfilled, sequencing was done utilizing AmpliSeq Cancer HotSpot Panel v2 for Illumina. Results in FASTQ format were quality-checked with FASTQC (v.0.9.5; http://www.bioinformatics.babraham.ac.uk/projects/fastqc/) and aligned against Genome Reference Consortium Human Reference 38 (GRCh38). Variant calling was done using LoFreq and annotated with SNPEFF and filtered with SNPSift. Annotation results were stored in variant call format (VCF) file.

\section{Inclusion criteria, exclusion criteria, and identification of pathogenic mutation}

a. Retrieval of VFC files fullfiling inclusion and exclusion criteria

- Inclusion criteria: FFPE samples fulfilling DNA purity criterion and showing PASS status in FASTQC

- Exclusion criteria: none

b. Data filtering based on estimation of putative impact or deleteriousness showing HIGH.

c. Identification of single nucleotide variant (SNV) and synchronization with 3 databases

- ClinVar (https://www.ncbi.nlm.nih.gov/clinvar/)

- COSMIC (https://cancer.sanger.ac.uk/cosmic)

- The Ensembl project (https://asia.ensembl.org/info/index.html) 
d. Identification of somatic effect based on American College of Medical Genetics (ACMG) classification and Functional Analysis through Hidden Markov Models (FATHMM) score.

e. Selection of SNVs meeting pathogenic criteria (ACMG pathogenic variant and/or FATHMM score $\geq 0,7$. f. Identification of SNVs of APC, TP53, PIK3CA, KRAS, and MLH1

g. Matching samples' numbers and medical record data

\section{Results}

\section{Patients characteristics}

Twenty two samples were collected in accordance with sample preparation procedures mentioned above. Among these samples, $41 \%$ (9/22) were diagnosed with stage $3 \mathrm{~b}$ of which 7 were elective cases. Fiftynine percent $(13 / 22)$ had lymphovascular invasion, of which 1 was diagnosed with stage $2 \mathrm{~A}$, and 12 were in stage 3B-4C.

\section{Pathogenic mutation mapping in whole chromosomes}

There were pathogenic mutation in almost all somatic chromosomes except 6, 9, 14, 16, 21, and 22 which involved 25 genes and 641 SNV (Table 2). Three types of mutation were identified i.e. synonymous (silent mutation); non-synonymous (nonsense, missense, and frameshift); and splice-site mutation.

\section{Pathogenic mutation mapping of APC, TP53, PIK3CA, KRAS, and MLH1}

Two types of APC pathogenic mutation occurred concurrently (nonsense and missense) in 1 patient. TP53 mutation also have 5 concurrent mutations in 1 patient (nonsense, missense, frameshift, silent, and splice-site) and only 3 of 22 patients having singular missense mutation. Only 1 type of pathogenic mutation occurring in MLH1 (nonsense) and PIK3CA (missense). Singular KRAS mutation occurred in 10 patients (8 missense and 2 silent) and multiple mutations occurred in 4 patients (Table 3 ).

Co-occurring mutation in more than 3 genes were presented in all subjects. Combination of triple mutation (APC, TP53, PIKCA) occurred in 4 of 22 patients. Combination of quintuple mutation (APC, TP53, PIKCA, KRAS, MLH1) occurred in 6 of 22 patients.

\section{APC mutation}

Gene mutation occurred in 100\% subjects with 17 SNVs (16 missense and 1 nonsense). Mutation cluster region (MCR) were located in exon 14-17. Median of SNV frequency was 4 (range 1-10). Most frequently 


\section{KRAS mutation}

In this study, KRAS mutation occurred in 14 of 22 patients $(63,6 \%)$. Nine SNVs were identified in 3 types of mutations i.e. missense, nonsense, and silent. Nonsense mutation cause termination of codon 22 , missenses occurred in 6 codons, and silent in 2 codons. Most frequently occurred SNVs are T20 $=$ in 4 subjects, A146T and P34L in 3 subjects (Table 5).

\section{TP53 mutation}

TP53 mutation also occurred in 100\% subjects in with 65 SNVs categorized into 5 types of mutations i.e. (1) missense, (2) nonsense; (3) frameshift; (4) silent; (5) splice-site. In missense mutation, 2 most frequent SNVs are M237I and C238Y. In nonsense mutation, 2 most frequent SNVs are R342* and R213* (6 of 22 patients) (Table 5).

\section{PIK3CA mutation}

Mutation of PIK3CA occurred in exon 2, 5, 7, 8, 10, 19, and 21. In this study PIK3CA missense mutation were identified in all subjects. Median of SNV frequency was 4 (range 1-16). Most frequently occurred SNV was G914R (Table 5).

\section{MLH1 Mutation}

MLH1 mutation occurred in 10 of $22(45,45 \%)$ subjects. Nonsense mutation occurred in exon 9-13 causing termination in 4 codons. Most frequently occurred SNV was Q391* (Table 5).

\section{Biological behavior of malignancy with co-occurring mutation (Table 6)}

Co-occurring mutation of APC, TP53, PIK3CA, and KRAS were identified in 8 patients with average age of 48,5 years old, with locally-advanced stage $(n=5)$, located in rectum $(n=6)$, well-differentiated $(n=6)$, and positive lymphovascular invasion $(n=5)$.

Co-occurring mutation of APC, TP53, PIK3CA, and MLH1 were identified in 4 patients, with average age of 52,3 years old, with locally advanced stage $(n=3)$, located in rectum $(n=3)$, without lymphovascular invasion. 
Quintuple mutation were identified in 6 patients, dominated by older age, locally-advanced stage, welldifferentiated, positive lymphovascular invasion, and located in rectum or left colon.

\section{Survival}

Patients with co-occurring mutation of APC, TP53, PIK3CA, and MLH1 (cluster 3) had the longest median life expectancy (1197 days) compared to cluster 2 with shortest median life expectancy (577 days) (Table 4, Figure 1).

Fifty percent of subjects of cluster 1 and 2 were deceased in less than 6 months after therapy, in cluster 4 , $50 \%$ of subjects were deceased before month 15. All patients of cluster 3 can survive up to 30 months after therapy and only 1 patient deceased afterwards. Cluster 2 and 4 shows highest mortality rate with highest number of deceased patients in shortest period compared to other clusters (Figure 2).

\section{Other findings}

Early recurrence ( $<5$ years) occurred in 2 patients of cluster 4 , of which 1 patient underwent neoadjuvant chemoradiation and adjuvant chemotherapy (MFOLFOX6) and another was given XELOX after surgery. Both patients have disease-free interval of 15 months.

One patient was given anti-EGFR therapy (cetuximab) + MFOLFOX6. Patient's PCR result for KRAS was wild-type. There is no data of therapeutic response due to patient's death during midcycle (127 days after surgery). This patient was included in cluster 2 (with KRAS mutation) and also had EGFR mutation (rs121913467).

One patient was given anti-VEGF therapy (bevacizumab) + MFOLFOX6 after diagnosed with local recurrence after 1-year of oral capecitabine. This patient was included in cluster 3 with noted BRAF mutation as well (rs121913353). Patients was known to have complete response to bevacizumab.

Two of 22 patients had family history of malignancy (Table 1). In patient with family history of colon cancer, there was 1 germline mutation identified in STK11, meanwhile in patient with family history of breast cancer, 2 germline TP53 mutations were identified.

\section{Discussion}

Colorectal cancer (CRC) patients in Indonesia are dominated by male (59\%), more than 50 years old (59\%), with well-differentiated (59\%), stage 3B (40,9\%), located in rectum (68\%). Recently, incidence of CRC in young adults increased by $1,4 \%$ per year influenced by obesity and sedentary life style. ${ }^{13}$ High percentage of locally-advanced stage on hospital admission can be caused by low educational level about CRC risk factors and importance of screening especially in individuals with family history of malignancy. Intricate system of national health insurance also has role in slacking patients with 
unspecific complaints to see doctors before having clear disorder and getting worse. These are several of many reasons that cause delay in diagnosis and management of CRC.

The heterogeneous and dynamic nature of the CRC are related with its overlapping pathways of carcinogenesis. There are 4 principles of neoplasia in CRC, (1) colorectal tumors arise due to the activation of proto-oncogene mutations into oncogenes and inactivation of tumor suppressor genes ${ }^{14}$; (2) at least mutations in 4-5 genes are required for malignant formation; (3) accumulation of numbers is more important than sequence of mutations in determining tumor biologic behavior; (4) the mutated tumor suppressor gene continues to express the phenotype without loss of heterozygosity. ${ }^{2}$

The theory of colorectal neoplasia, namely adenoma-carcinoma sequence (ACS) states that the formation of colorectal carcinoma must be preceded by the presence of an adenoma. ${ }^{1,2}$ Changes in the normal intestinal mucosal epithelium to adenoma are triggered by mutations in the tumor suppressor gene, that is APC. APC can be detected in the aberrant crypt foci (ACF), which is a precursor lesion that occurred early in the beginning of the formation of adenomatous polyps and can only appear in dysplastic lesions. ${ }^{15}$

All subjects $(100 \%)$ in this study had nonsynonymous mutations in APC. Only 2 patients had adenomas on colonoscopy. One of those had tubulous adenomas with mild dysplasia on colonoscopy and firstdegree relative with CRC. Nonsense mutated APC was found at codons $879,1095,1123$, which completely stopped glutamine production (Q). Meanwhile, in another patient with villous adenomas and well-differentiated adenocarcinoma, nonsense mutations were found at codons 876, 879, 1096, 1291, 1294 and 1517 that stopped the production of the amino acids glutamine (Q) and arginine (R). Mutations in APC are known to have high-penetrance that can reach $100 \%$ for FAP and CRC. ${ }^{16-19}$ In contrast to the Japanese population, whose APC mutations scattered at codons 142-1513, subjects in this study had APC mutations occur at codons 876-1517 with mutation cluster region (MCR) in exons $14-17 .{ }^{20,21}$

After the normal mucosal epithelium turned into an early adenoma, KRAS mutation occurred subsequently triggering the change of early into intermediate adenoma. However, in contrast to APC, KRAS can act on nondysplastic ACF precursor lesions. ${ }^{15}$

In this study, mutations in the KRAS gene occurred in 14 of 22 samples $(63.6 \%)$ at 9 codons and were most commonly found in older age group, locally-advanced stage, well-differentiated/low grade, with positive lymphovascular invasion, and located at the rectum. There were differences of codon location in missense mutation between Jakarta (Indonesia) and United States population, i.e. codons 13, 14, 34, 58, 59,146 VS 12, 13, 61, 146.22 In addition, nonsense mutations were also found at codon 22 which only occurred in 1 patient. This patient diagnosed with stage 2A (pT3NOM0) undergoing elective curative resection and was given 8 cycles of capecitabine adjuvant chemotherapy with complete response. Mutation located in codon 12 has more aggressive behavior than codon 13, because patients were commonly presented in advanced stage. ${ }^{22}$ Nevertheless, number of cases with metastases involving KRAS mutation in this study was found in 3 of 5 samples without involvement of codon 12 . 
KRAS mutation can occur concomitantly with APC mutation leading to increased accumulation of $\beta$ cathenin in the cytoplasm, by destroying its binding to E-cadherin, which has actually been increased due to loss of mutated APC degradation function. This causes the Wnt signal to become more active so that motility and cell invasion are more aggressive. ${ }^{15,18,21,23-26}$ In CRC, the combination of APC and KRAS mutations (co-occurring mutations) can occur up to $80 \%$, whereas in this study only occurred in $63.6 \%$ of subjects. $^{27}$

In this study, patients with APC, TP53 and KRAS mutations were predominantly $\geq 50$ years old, with locally-advanced stage and positive lymphovascular invasion. Two shortest median life expectancy were found in patients with KRAS mutation (Fig. 1), in addition $50 \%$ of patients died within 6 months after therapy (Fig. 2).

Before turning into carcinoma, intermediate adenomas differentiate into late adenomas triggered by mutations in the SMAD4, CDC4, and DCC genes. ${ }^{2,7}$ In this study, we found SMAD4 nonsense and missense mutations in 18 of 22 patients (82\%).

In ACS theory, late adenomas who developed into carcinomas have mutations in TP53, TGFBR2, BAX, and IGF2R. Mutated TP53 was found in all subjects in this study in the form of nonsense, missense, frameshift, splice-site, and silent mutation. Five most frequently occurred codon locations in this study were 237, 238, 127, G245S, and R248Q. Those are different compared to world database in The Cancer Genome Atlas Program (TCGA) portal which stated that the five codon positions with the highest frequency were $175,282,248, \mathrm{R} 273 \mathrm{H}$, and R273C. ${ }^{28}$

In contrast to the UK population, in $64 \%$ (14 out of 22 ) subjects, TP53 and KRAS mutations cooccurred. ${ }^{18,21}$ In Indian population, these two combinations were only found in 13 of 112 cases, whereas the study by Timar can occur in up to 40\%. ${ }^{27,29}$ TP53 and KRAS activate different carcinogenesis pathways so that they rarely coexist. ${ }^{30}$

Similar to APC and TP53, PIK3CA mutations were found in all subjects $(100 \%)$ with 9 SNVs. PIK3CA has no role in the aggressive behavior of CRC. ${ }^{31,32}$ Even so, when it occurs concurrently with KRAS mutations, it will show evident aggressive behavior, especially when occurs in exons 9 and 20. While in this study mutations occurred in exons 2, 3, and 4, aggressive behavior presenting as locally-advanced stage and positive lymphovascular invasion can be found.

Mutations in MLH1 can also occur in non-hereditary/sporadic CRC. The existence of microsatellite instability due to mutations in genes that play roles in the MMR system such as MLH1 actually provides a good prognosis with a higher survival rate. ${ }^{33}$ In this study, the group of cases with MLH1 mutations alone, had the highest median life expectancy and had a 30 -month survival rate of up to $100 \%$.

Referring to the colorectal neoplasia principle mentioned above, all subjects in this study indeed involved activation of oncogenes (PIK3CA and KRAS) and inactivation of tumor suppressor genes (APC, TP53 and 
MLH1) and also involved a range of 8-19 mutated genes per person. In this study, mutated APC and KRAS, which supposed to be occurred on early sequence of ACS, supports what Fearon stated about unimportance of mutational sequence in determining tumor biologic behavior. ${ }^{1,2}$

This is the first study fully describes the profile of pathogenic mutations of CRC in Indonesian population with its unique characteristics, compiled of various ethnicities with diverse diet and lifestyle which may have roles in contributing natures of Indonesian version of CRC presenting in locally-advanced stage with large tumor size and moderate-severe malnutrition status. This study is also the first in the world to examine the co-occurring mutations of APC, TP53, PIK3CA, KRAS, and MLH1.

\section{Conclusions}

1. Different profile of pathogenic mutation in colorectal cancer patients is found in Indonesia's population

2. Mutated APC, TP53, and PIK3CA occurred in $100 \%$ subjects, while KRAS and MLH1 occurred in $63,6 \%$ and $45,4 \%$ subjects

3. The longest median life expectancy occurred in the group of patients with mutations APC, TP53, PIK3CA, and MLH1 with a 30-month postoperative survival of $100 \%$.

4. The shortest median life expectancy occurred in the group of patients with APC, TP53, PIK3CA, and KRAS mutations with a $50 \%$ life expectancy $<6$ months post-treatment.

\section{Abbreviations}

ACF : aberrant crypt foci

ACMG: American College of Medical Genetics

ACS : adenoma-carcinoma sequence

AJCC : American Joint Committee on Cancer

APC : Adenomatous Polyposis Coli

BAX : Bcl-2 Associated X protein

CDC4 : Cell division control protein 4

CRC : colorectal cancer

DCC : deleted in colorectal cancer

DNA : deoxyribonucleic acid

EGFR : Epidermal Growth Factor Receptor 
FAP : Familial Adenomatous Polyposis

FATHMM : Functional Analysis through Hidden Markov Models

FFPE : Formalin-fixed Paraffin-Embedded

GRCh38 : Genome Reference Consortium Human Reference 38

IGF2R : Insulin Like Growth Factor 2 Receptor

KRAS : Kirsten rat sarcoma viral oncogene

MFOLFOX6 : modified Folinic Acid + 5-Fluorouracil + Oxaliplatin

MLH1 : MutL Homolog 1

MMR : mismatch repair

PIK3CA : Phosphatidylinositol-4,5-Bisphosphate 3-Kinase Catalytic Subunit Alpha

SMAD4 :SMAD family member 4, Mothers against decapentaplegic homolog 4

SNPEFF : SNP Effect

SNV : Single Nucleotide Variant

TGFBR2 : Transforming Growth Factor Beta Receptor 2

TP53 : Tumor Protein 53

VCF : Variant Call Format

VEGF : Vascular Endothelial Growth Factor

Wnt : Wingless-related integration site

\section{Declarations}

\section{Ethical Approval}

The Ethics Committee of the Faculty of Medicine, Universitas Indonesia - RSUPN Cipto Mangunkusumo with regards of the Protection of human rights and welfare in medical research, has carefully reviewed the research with registry number: KET-445/UN2.F1/ETIK/PPM.00.02/2021. All procedures of Ethical Approval are performed in accordance with ICH-GCP standard procedure. 


\section{Declarations}

Authors declare no conflict of interest. Provenance and peer review. Not commissioned, externally peerreviewed.

\section{Availability of data and materials}

The datasets generated and/or analysed during the current study are not publicly available due to presence of individuals' personal details but are available from the corresponding author on reasonable request.

\section{Authors' Contribution}

VMGM analysed and interpreted data related to colorectal cancer, gathered information in medical records, and synchronized patients' data with VCF data files, and was a major contributor in writing the manuscript.

LE carried out the molecular genetics study and participated in sequence alignment.

TJML participated in its design and coordination and helped to draft the manuscript.

All authors read and approved the final manuscript.

\section{Consent for publication}

Consent was not required in this study because no details on individuals reported within the manuscript. This was already reviewed by the Ethics Committee mentioned above.

\section{Acknowledgment}

Not applicable

\section{Competing Interest}

Not applicable

\section{Funding}

No funding was obtained in this study. 


\section{References}

1. Vogelstein B, Fearon ER, Hamilton SR, Kern SE, Preisinger AC. Genetic Alterations During ColorectalTumor Development. N Engl J Med. 1988;319(9). doi:10.1097/00043764-198910000-00001

2. Fearon ER, Vogelstein B. A Genetic Model for Colorectal Tumorigenesis. Cell. 1990;61:759-767.

3. Sagaert X, Vanstapel A, Verbeek S. Tumor Heterogeneity in Colorectal Cancer: What Do We Know So Far? Pathobiology. 2018;85(1-2):72-84. doi:10.1159/000486721

4. Molinari C, Marisi G, Passardi A, Matteucci L, De Maio G, Ulivi P. Heterogeneity in colorectal cancer: A challenge for personalized medicine? Int J Mol Sci. 2018;19(12). doi:10.3390/ijms19123733

5. Hiley CT, Swanton C. Spatial and temporal cancer evolution: causes and consequences of tumour diversity. Clin Med. 2014;14(6):s33-s37. doi:10.7861/clinmedicine.14-6-s33

6. Del Vecchio F, Mastroiaco V, Di Marco A, et al. Next-generation sequencing: Recent applications to the analysis of colorectal cancer. J Transl Med. 2017;15(1):1-19. doi:10.1186/s12967-017-1353-y

7. Nguyen HT, Duong HQ. The molecular characteristics of colorectal cancer: Implications for diagnosis and therapy (review). Oncol Lett. 2018;16(1):9-18. doi:10.3892/ol.2018.8679

8. Tariq K, Ghias K. Colorectal cancer carcinogenesis: a review of mechanisms. Cancer Biol Med. 2016;13(1):120-135. doi:10.28092/j.issn.2095-3941.2015.0103

9. Kang S, Na Y, Joung SY, Lee S II, Oh SC, Min BW. The significance of microsatellite instability in colorectal cancer after controlling for clinicopathological factors. Med (United States). 2018;97(9):16. doi:10.1097/MD.0000000000010019

10. Harada S, Morlote D. Molecular Pathology of Colorectal Cancer. Adv Anat Pathol. 2020;27(1):20-26. doi:10.1097/PAP.0000000000000247

11. Nagahashi M, Wakai T, Shimada Y, et al. Genomic landscape of colorectal cancer in Japan: Clinical implications of comprehensive genomic sequencing for precision medicine. Genome Med. 2016;8(1):1-13. doi:10.1186/s13073-016-0387-8

12. Agha R, Abdall-Razak A, Crossley E, Dowlut N, losifidis C, Mathew G. STROCSS 2019 Guideline: Strengthening the reporting of cohort studies in surgery. Int J Surg. 2019;72(October):156-165. doi:10.1016/j.ijsu.2019.11.002

13. Venugopal A, Stoffel EM. Colorectal cancer in young adults. In: Current Treatment Options in Gastroenterology. Vol 17. Current Treatment Options in Gastroenterology; 2019:89-98. doi:10.1007/s11938-019-00219-4

14. Bunz F. Principles of Cancer Genetics.; 2008. doi:10.1007/978-1-4020-6784-6

15. Janssen KP, Alberici P, Fsihi $\mathrm{H}$, et al. APC and Oncogenic KRAS Are Synergistic in Enhancing Wnt Signaling in Intestinal Tumor Formation and Progression. Gastroenterology. 2006;131(4):10961109. doi:10.1053/j.gastro.2006.08.011

16. Jasperson KW, Patel SG, Ahnen DJ. APC -Associated Polyposis Conditions Summary Clinical characteristics Diagnosis Suggestive Findings. 2019:1-38. 
17. Fearnhead NS, Britton MP, Bodmer WF. The ABC of APC. Hum Mol Genet. 2001;10(7):721-733. doi:10.1093/hmg/10.7.721

18. Conlin A, Smith G, Carey FA, Wolf CR, Steele RJC. The prognostic significance of K-ras, p53, and APC mutations in colorectal carcinoma. Gut. 2005;54(9):1283-1286. doi:10.1136/gut.2005.066514

19. Win AK, Jenkins MA, Dowty JG, et al. Prevalence and penetrance of major genes and polygenes for colorectal cancer. Cancer Epidemiol Biomarkers Prev. 2017;26(3):404-412. doi:10.1158/10559965.EPI-16-0693

20. Miyoshi $Y$, Nagase $H$, Ando $H$, et al. Somatic mutations of the APC gene in colorectal tumors: Mutation cluster region in the APC gene. Hum Mol Genet. 1992;1(4):229-233. doi:10.1093/hmg/1.4.229

21. Smith G, Carey FA, Beattie J, et al. Mutations in APC, Kirsten-ras, and p53-alternative genetic pathways to colorectal cancer. Mutat Res - Fundam Mol Mech Mutagen. 2002;99(14):9433-9438. doi:10.1016/j.mrfmmm.2009.06.011

22. He K, Wang Y, Zhong Y, Pan X, Si L, Lu J. Kras codon 12 mutation is associated with more aggressive invasiveness in synchronous metastatic colorectal cancer (Mcrc): Retrospective research. Onco Targets Ther. 2020;13:12601-12613. doi:10.2147/OTT.S279312

23. Tian X, Liu Z, Niu B, et al. E-Cadherin/ $\beta$-catenin complex and the epithelial barrier. J Biomed Biotechnol. 2011;2011. doi:10.1155/2011/567305

24. Harington KJ, Syrigos KN. The role of E-cadherin-catenin complex: More than an intercellular glue? Ann Surg Oncol. 2000;7(10):783-788. doi:10.1007/s10434-000-0783-5

25. llyas $\mathrm{M}$, Tomlinson IPM. The interactions of APC, E-cadherin and $\beta$-catenin in tumour development and progression. J Pathol. 1997;182(2):128-137. doi:10.1002/(SICI)10969896(199706)182:2<128::AID-PATH839>3.0.C0;2-Q

26. Zhan T, Rindtorff N, Boutros M. Wnt signaling in cancer. Oncogene. 2017;36(11):1461-1473. doi:10.1038/onc.2016.304

27. Timar J, Kashofer K. Molecular epidemiology and diagnostics of KRAS mutations in human cancer. Cancer Metastasis Rev. 2020;39(4):1029-1038. doi:10.1007/s10555-020-09915-5

28. Grossman RL, Heath AP, Ferretti V, et al. Toward a Shared Vision for Cancer Genomic Data. N Engl J Med. 2016;375(12):1109-1112. doi:10.1056/NEJMp1607591.Toward

29. Jauhri M, Bhatnagar A, Gupta S, et al. Prevalence and coexistence of KRAS, BRAF, PIK3CA, NRAS, TP53, and APC mutations in Indian colorectal cancer patients: Next-generation sequencing-based cohort study. Tumor Biol. 2017;39(2). doi:10.1177/1010428317692265

30. Pino MS, Chung DC. THE CHROMOSOMAL INSTABILITY PATHWAY IN COLON. Gastroenterol 138(6) 2059-2072. 2010;138(6):2059-2072. doi:10.1053/j.gastro.2009.12.065.THE

31. Jin J, Shi Y, Zhang S, Yang S. PIK3CA mutation and clinicopathological features of colorectal cancer: a systematic review and Meta-Analysis. Acta Oncol (Madr). 2020;59(1):66-74.

doi:10.1080/0284186X.2019.1664764 
32. Jang S, Hong M, Shin MK, et al. KRAS and PIK3CA mutations in colorectal adenocarcinomas correlate with aggressive histological features and behavior. Hum Pathol. 2017;65:21-30. doi:10.1016/j.humpath.2017.01.010

33. Wang SM, Jiang B, Deng Y, Huang SL, Fang MZ, Wang Y. Clinical significance of MLH1/MSH2 for stage II/III sporadic colorectal cancer. World J Gastrointest Oncol. 2019;11(11):1065-1080. doi:10.4251/wjgo.v11.i11.1065

\section{Tables}

\section{Table 1}

Patients characteristics 


\begin{tabular}{|c|c|c|c|}
\hline \multicolumn{2}{|l|}{ Variables } & \multirow{2}{*}{$\begin{array}{l}\text { Numbers } \\
9\end{array}$} & \multirow{2}{*}{$\begin{array}{l}\% \\
41\end{array}$} \\
\hline Age & $<50$ y.o. & & \\
\hline & $\geq 50$ y.o. & 13 & 59 \\
\hline \multirow[t]{2}{*}{ Gender } & Male & 13 & 59 \\
\hline & Female & 9 & 41 \\
\hline \multirow[t]{2}{*}{ Death } & Yes & 11 & 50 \\
\hline & No & 11 & 50 \\
\hline \multirow[t]{3}{*}{ Grade } & Well & 13 & 59 \\
\hline & Moderate & 6 & 27 \\
\hline & Poor & 3 & 14 \\
\hline \multirow[t]{4}{*}{ Stage } & 1 & 2 & 9,1 \\
\hline & $2 \mathrm{~A} / \mathrm{B} / \mathrm{C}$ & $5 / 1 /-$ & 27,3 \\
\hline & $3 \mathrm{~A} / \mathrm{B} / \mathrm{C}$ & $-/ 9 /-$ & 40,9 \\
\hline & $4 \mathrm{~A} / \mathrm{B} / \mathrm{C}$ & $2 / 1 / 2$ & 22,7 \\
\hline \multirow{2}{*}{$\begin{array}{l}\text { Lymphovascular } \\
\text { invasion }\end{array}$} & Yes & 13 & 59 \\
\hline & No & 9 & 41 \\
\hline \multirow[t]{3}{*}{ Tumor location } & Group 1 & 3 & 14 \\
\hline & Group 2 & 4 & 18 \\
\hline & Group 3 & 15 & 68 \\
\hline \multirow{4}{*}{$\begin{array}{l}\text { Perioperative } \\
\text { management }\end{array}$} & None & 13 & 59 \\
\hline & Neoadjuvant chemoradiation & - & - \\
\hline & Adjuvant chemotherapy & 7 & 32 \\
\hline & $\begin{array}{l}\text { Neoadjuvant chemoradiation + adjuvant } \\
\text { chemotherapy }\end{array}$ & 2 & 9 \\
\hline \multirow[t]{2}{*}{ Family history of cancer } & Colon cancer & 1 & 9 \\
\hline & Breast cancer & 1 & \\
\hline \multicolumn{2}{|c|}{ Average interval from diagnosed to death } & \multicolumn{2}{|c|}{259 hari (3-882) } \\
\hline
\end{tabular}


Table 2

Pathogenic mutation mapping

\begin{tabular}{|c|c|c|c|c|c|c|c|c|c|c|c|c|c|c|c|c|c|c|c|c|c|c|c|c|c|}
\hline $\mathrm{Chr}$ & 1 & & 2 & & & 3 & & & 4 & 5 & 7 & & 8 & 1 & 0 & 11 & 12 & 13 & 15 & 17 & 18 & 19 & 20 & \multirow{2}{*}{$\begin{array}{c}\text { Total } \\
\text { Genes }\end{array}$} & \multirow{2}{*}{$\begin{array}{l}\text { Total } \\
\text { SNVs }\end{array}$} \\
\hline Gene & a & $\mathrm{b}$ & c d & e & e & $\mathrm{f}$ & g & $\mathrm{h}$ & $\mathrm{i}$ & $\mathbf{j}$ & $\mathrm{k}$ & 1 & $\mathrm{~m}$ & $\mathrm{n}$ & o $p$ & $q$ & $\mathbf{r}$ & $\mathrm{s}$ & $\mathrm{t}$ & $\mathbf{u}$ & $\mathrm{v}$ & $\mathrm{w}$ & $x$ & & \\
\hline \multicolumn{26}{|l|}{ Pts } \\
\hline 1 & & & & & 2 & & 2 & & 1 & 1 & & 2 & & & & & 2 & 1 & & 4 & 5 & 1 & & 10 & 21 \\
\hline 2 & & & & & 1 & 1 & 1 & & 1 & 3 & 1 & & & 1 & $\begin{array}{ll}1 & 1\end{array}$ & & & 4 & 1 & 10 & 1 & & 1 & 15 & 29 \\
\hline 3 & 1 & & & & & 2 & 1 & & 2 & 3 & 1 & 1 & & & & & & 1 & & 7 & & & & 9 & 19 \\
\hline 4 & 1 & 1 & & & & & 1 & & 1 & 3 & & & & & & & & 1 & & 3 & & 1 & & 8 & 12 \\
\hline 5 & 1 & & 2 & 1 & 1 & & 1 & 1 & & 2 & 1 & & & 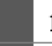 & 1 & & & 1 & & 4 & 2 & & & 11 & 17 \\
\hline 6 & & & & 1 & 1 & & 2 & & & 2 & 1 & & & 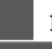 & 1 & & & 1 & & 4 & 1 & & & 8 & 13 \\
\hline 7 & & & 2 & & & 2 & 2 & & 1 & 4 & 2 & 1 & & & & 1 & 2 & 4 & 1 & 14 & 2 & 1 & 1 & 15 & 40 \\
\hline 8 & & & 1 & 2 & 2 & 1 & 1 & & 3 & 2 & & & & & & & 1 & 5 & 1 & 9 & 2 & 1 & & 12 & 29 \\
\hline 9 & 1 & & & 1 & 1 & & 3 & & 2 & 1 & & & & & & & & 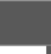 & & 9 & 1 & & & 8 & 19 \\
\hline 10 & & & & 1 & 1 & 2 & 2 & & & 1 & & 1 & & & & & & 4 & & 4 & 1 & & 1 & 9 & 17 \\
\hline 11 & & & 1 & & & 1 & 1 & & & 3 & 2 & 1 & & 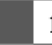 & 1 & & 1 & 1 & & 4 & . & 1 & 1 & 12 & 18 \\
\hline 12 & 1 & 1 & & 2 & 2 & 1 & 2 & & & 6 & 1 & 2 & 1 & 1 & 1 & 1 & & 3 & & 10 & 1 & 1 & & 17 & 36 \\
\hline 13 & 1 & 1 & & & & 1 & 2 & & 2 & 5 & 2 & 2 & & 2 & 2 & & 1 & 3 & & 10 & 4 & & 1 & 15 & 38 \\
\hline 14 & 1 & & & 1 & 1 & & 1 & & & 3 & 1 & 1 & & & & 1 & 1 & 3 & & 7 & 1 & 2 & & 12 & 23 \\
\hline 15 & 1 & & 1 & 1 & 1 & 1 & 3 & & & 6 & 1 & 2 & & 1 & 1 & & 2 & 3 & & 9 & 4 & 1 & & 15 & 37 \\
\hline 16 & 1 & 2 & 1 & 3 & 3 & 2 & 2 & 1 & 1 & 7 & 5 & 2 & 1 & & 1 & 1 & 4 & 6 & & 9 & 4 & & 1 & 19 & 55 \\
\hline 17 & & & 1 & & 2 & & 4 & & 1 & 3 & 3 & 1 & & & 21 & & 1 & 4 & & 17 & 4 & 1 & 1 & 14 & 46 \\
\hline 18 & & 1 & 1 & 2 & 2 & & 2 & & 3 & 3 & 1 & & & 1 & 1 & 1 & 1 & 4 & 1 & 6 & 5 & & 1 & 17 & 35 \\
\hline 19 & 1 & & 1 & 1 & 1 & & 2 & & 1 & 3 & 1 & 1 & 1 & & & & 2 & 3 & 1 & 14 & 2 & 2 & & 16 & 37 \\
\hline 20 & & & & 2 & 2 & & 1 & & 1 & 1 & & 1 & & & & & 1 & 4 & & 13 & 6 & & & 9 & 30 \\
\hline 21 & & & & 2 & 2 & & 3 & & 1 & 4 & 2 & 1 & & 1 & & 1 & 1 & 4 & & 12 & & 1 & 1 & 13 & 34 \\
\hline 22 & & & 1 & 1 & 1 & & 2 & 1 & 2 & 1 & 1 & 2 & 1 & & 2 & & 1 & 6 & & 10 & 3 & 1 & 1 & 16 & 36 \\
\hline $\begin{array}{c}\text { Total } \\
\text { Patients }\end{array}$ & 10 & 5 & 9 & $\begin{array}{ll}2 & 17 \\
\end{array}$ & $17 \quad 1$ & 10 & 22 & 3 & 15 & 22 & 16 & 15 & 4 & 5 & 9 & 6 & 14 & 21 & 5 & 22 & 18 & 12 & 10 & 5 & 641 \\
\hline
\end{tabular}

Information:
a. NRAS
j. APC
s. RB1
b. ALK
k. BRAF
t. IDH2
c. IDH1
1. EGFR
u. TP53
d. ERBB4
m. FGFR1
v. SMAD4
e. VHL
n. RET
w. STK 11
f. MLH1
o. PTEN
x. SRC
g. $\mathrm{PIK} 3 \mathrm{CA}$
p. FGFR2
y. GNAS
h. CTNNB1
q. ATM
i. KIT
r. KRAS 
Table 3

Pathogenic mutation mapping of 5 genes

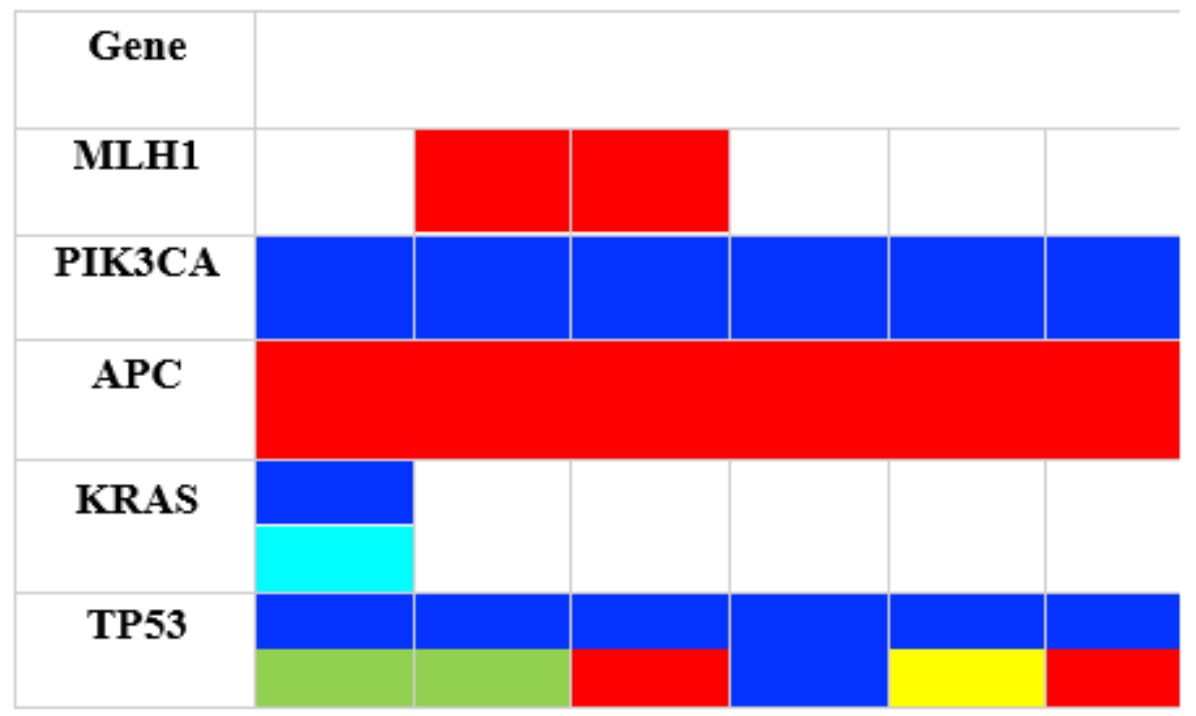

\begin{tabular}{l|l}
\hline Nonsense \\
\hline Missense \\
\hline Frameshift \\
\hline Splice-site \\
\hline Silent \\
\hline None
\end{tabular}

Table 4

Subjects with co-occurring mutation

\begin{tabular}{|ll|}
\hline Co-occurring mutation & Number of subjects \\
\hline APC + TP53 + PIK3CA + KRAS + MLH1 (cluster 1) & 6 \\
\hline APC + TP53 + PIK3CA + KRAS (cluster 2) & 8 \\
\hline APC + TP53 + PIK3CA + MLH1 (cluster 3) & 4 \\
\hline APC + TP53 + PIK3CA (cluster 4) & 4 \\
\hline Total & 22 \\
\hline
\end{tabular}


Table 5

Most frequent SNV in mutated genes

\begin{tabular}{|ll|}
\hline Gene & SNV \\
\hline APC & Q879* \\
\hline TP53 & R342* \\
& R213* \\
\hline PIK3CA & G914R \\
\hline KRAS & A146T \\
& P34L \\
\hline MLH1 & Q391* \\
\hline
\end{tabular}

Table 6

Clinical Manifestation of each combination of co-occurring mutations 


\begin{tabular}{|c|c|c|c|c|}
\hline & $\begin{array}{l}A P C+T P 53+ \\
P I K 3 C A+K R A S \\
\text { (Cluster 1) }\end{array}$ & $\begin{array}{l}\text { APC+TP53+ } \\
P I K 3 C A+\mathbf{M L H 1} \\
\text { (Cluster 2) }\end{array}$ & $\begin{array}{l}\text { APC + TP53 + PIK3CA } \\
+\mathrm{KRAS}+\mathrm{MLH1} \\
\text { (Cluster 3) }\end{array}$ & $\begin{array}{l}\text { APC + TP53 } \\
+P I K 3 C A \\
\text { (Cluster 4) }\end{array}$ \\
\hline & $n=8$ & $\mathrm{n}=4$ & $n=6$ & $\mathrm{n}=4$ \\
\hline $\begin{array}{l}\text { Age (mean) } \\
\text { (range) }\end{array}$ & $\begin{array}{l}\text { Mean 48,516 } \\
(27-75)\end{array}$ & $\begin{array}{l}\text { Mean } 52,319 \\
(27-67)\end{array}$ & $\begin{array}{l}\text { Mean } 58,713 \\
(40-74)\end{array}$ & $\begin{array}{l}\text { Mean } \\
56,322 \\
(39-87)\end{array}$ \\
\hline 50 у.о. & 4 & 3 & 4 & 2 \\
\hline 50 у.о. & 4 & 1 & 2 & 2 \\
\hline \multicolumn{5}{|l|}{ Stage } \\
\hline Early & 1 & 0 & 1 & 0 \\
\hline $\begin{array}{l}\text { Locally- } \\
\text { advanced }\end{array}$ & 5 & 3 & 4 & 3 \\
\hline Advanced & 2 & 1 & 1 & 1 \\
\hline \multicolumn{5}{|c|}{$\begin{array}{l}\text { Lymphovascular } \\
\text { invasion }\end{array}$} \\
\hline Yes & 5 & 0 & 4 & 4 \\
\hline No & 3 & 4 & 2 & 0 \\
\hline \multicolumn{5}{|c|}{ Tumor location } \\
\hline Group 1 & 1 & 1 & 0 & 1 \\
\hline Group 2 & 1 & 0 & 3 & 0 \\
\hline Group 3 & 6 & 3 & 3 & 3 \\
\hline \multicolumn{5}{|l|}{ Grade } \\
\hline Well & 6 & 2 & 5 & 0 \\
\hline Moderate & 1 & 0 & 0 & 2 \\
\hline Poor & 1 & 2 & 1 & 2 \\
\hline \multicolumn{5}{|l|}{ Mortality } \\
\hline Yes & 4 & 1 & 3 & 3 \\
\hline No & 4 & 3 & 3 & 1 \\
\hline
\end{tabular}

Figures 


\section{Median Life Expectancy (days)}

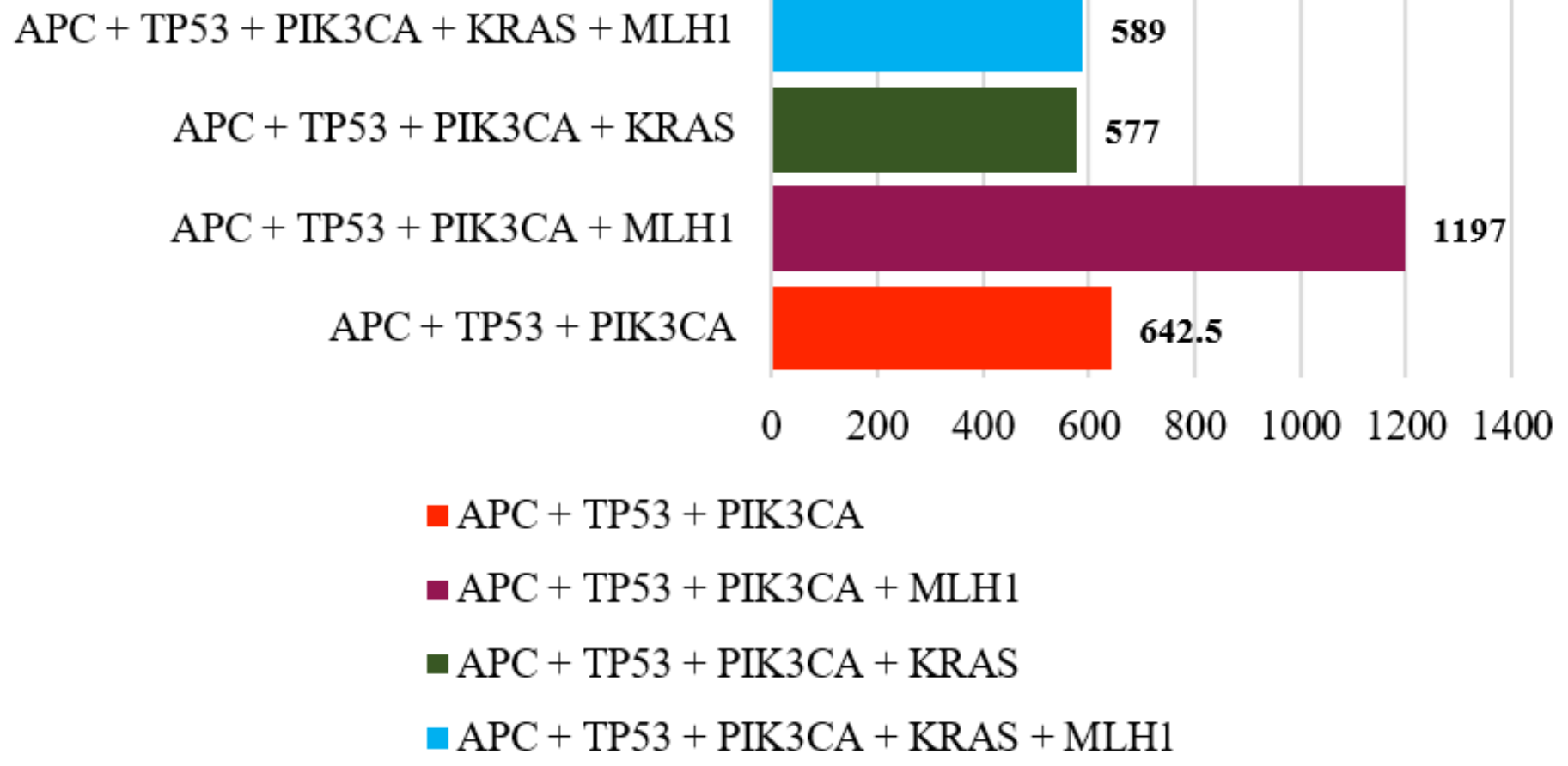

642.5

$\begin{array}{llllllll}0 & 200 & 400 & 600 & 800 & 1000 & 1200 & 1400\end{array}$

口 APC + TP53 + PIK3CA

- $\mathrm{APC}+\mathrm{TP} 53+\mathrm{PIK} 3 \mathrm{CA}+\mathrm{MLH} 1$

n APC + TP53 + PIK3CA + KRAS

口 APC + TP53 + PIK3CA + KRAS + MLH1

Figure 1

Median life expectancy 


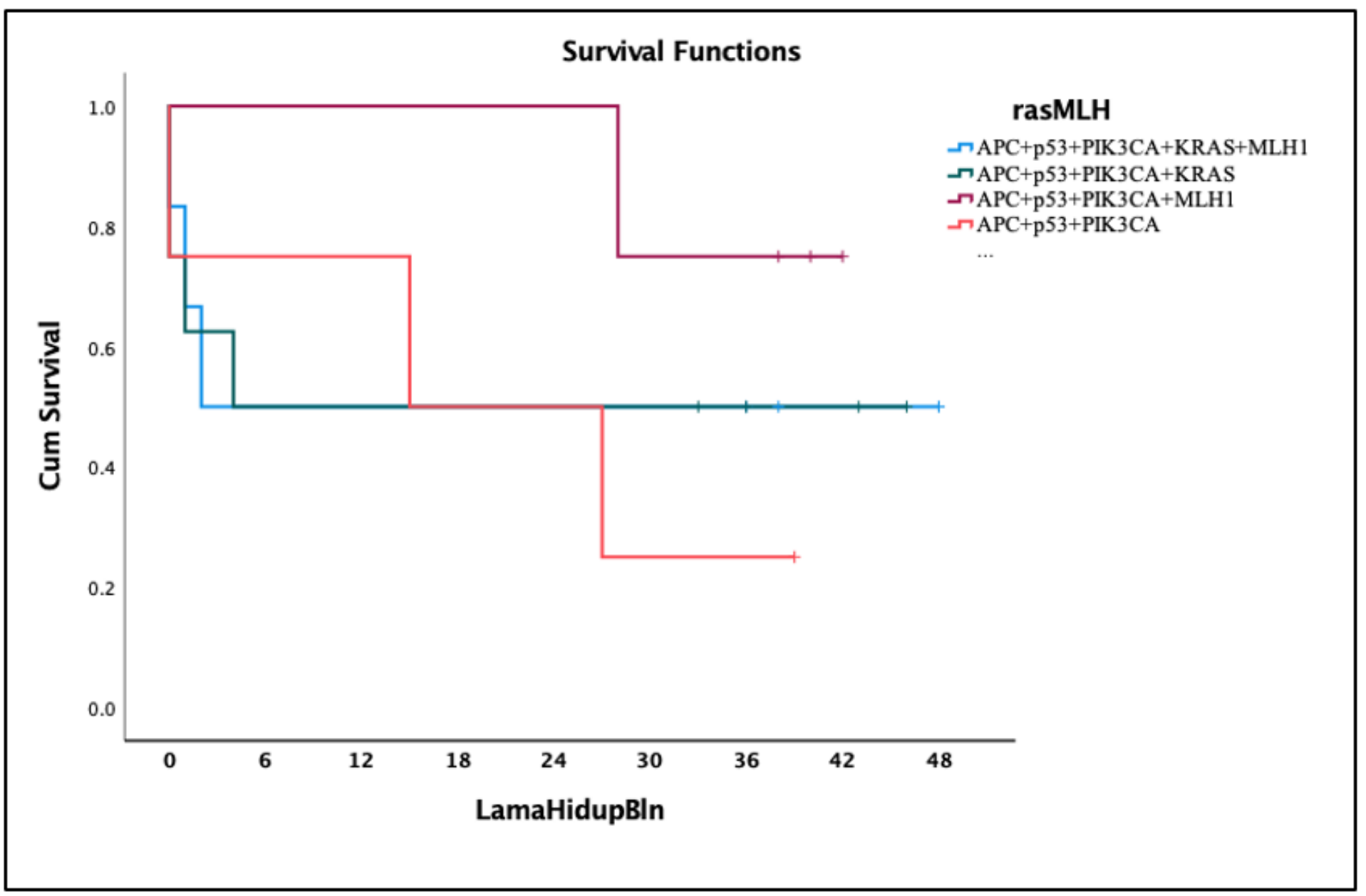

Figure 2

Survival rate based on co-occurring mutation 